\title{
IDENTIDADES PROFISSIONAIS EM CONSTRUÇÃO: CONJECTURAS SOBRE A ENFERMAGEM NO PÓS-PANDEMIA DE COVID-19
}

\author{
PROFESSIONAL IDENTITIES IN \\ CONSTRUCTION: CONJECTURES ABOUT NURSING \\ IN THE POST-PANDEMIC OF COVID-19
}

\section{IDENTIDADES PROFESIONALES EN CONSTRUCCIÓN: CONJETURAS SOBRE ENFERMERÍA EN LA POST-PANDEMIA DE COVID-19}

\author{
Ellen Maria Hagopian ${ }^{1}$ \\ Fábio Soares Melo $^{2}$ \\ Genival Fernandes de Freitas ${ }^{3}$ \\ Viviane Barrére Martin Taffner ${ }^{4}$ \\ Margarete Maria Rodrigues ${ }^{5}$ \\ Marcus Vinícius de Lima Oliveira ${ }^{6}$
}

Como citar este artigo: Hagopian EM, Melo FS, Freitas GF, Taffner VBM, Rodrigues MM, Oliveira MVL. Identidades profissionais em construção: conjecturas sobre a enfermagem no pós-pandemia de COVID-19. Rev baiana enferm. 2021;35:e42883.

Objetivo: compreender as percepções dos profissionais de enfermagem em relação aos possíveis desfechos decorrentes da pandemia da COVID-19 para a profissão. Método: estudo de abordagem qualitativa, fundamentada na História Oral, mediante entrevista e aplicação de um questionário socioeconômico/profissional, realizado na unidade de internação de uma instituição de saúde de grande porte, localizada no município de São Paulo, capital do estado de São Paulo. Resultados: foram extraídas das entrevistas duas categorias relevantes: Crença no fortalecimento da enfermagem no pós-pandemia e Descrença na melhora da imagem da enfermagem no pós-pandemia. Considerações Finais: as identidades profissionais são construídas mediante as interações sociais entre o eu (indivíduo) e o outro (grupos sociais e institucionais). Esta interação é marcada por conflitos que resultam na reconstrução desta identidade e com possíveis reflexos na prática profissional.

Descritores: História da Enfermagem. Enfermagem. Construção Social da Identidade. Identidade Própria. Crise de Identidade.

\footnotetext{
Enfermeira. Doutora na área de Gerenciamento em Enfermagem pela Universidade de São Paulo. São Paulo, São Paulo, Brasil. ellen_hagopian@yahoo.com.br. http://orcid.org/0000-000I-5966-0I59.

2 Enfermeiro. Mestre em Ciências, área Fundamentos e Práticas de Gerenciamento em Enfermagem e em Saúde. Escola de Enfermagem de São Paulo. São Paulo, São Paulo, Brasil. http://orcid.org/0000-0003-4028-9534.

Enfermeira. Professora Titular da Escola de Enfermagem da Universidade de São Paulo. São Paulo, São Paulo, Brasil. http://attes.cnpq.br/l30492824932971 .

Enfermeira. Mestre em Enfermagem. Escola de Enfermagem da Universidade de São Paulo. São Paulo, São Paulo, Brasil. http://lattes.cnpq.br/9330152636 78040

5 Enfermeira. Mestre em Ciências, área Fundamentos e Práticas de Gerenciamento em Enfermagem e em Saúde. Escola de Enfermagem da Universidade de São Paulo. São Paulo, São Paulo, Brasil. http://lattes.cnpq.br/I I 515263190। 8234

6 Enfermeiro. Mestre em Ciências, área Fundamentos e Práticas de Gerenciamento em Enfermagem e em Saúde. Escola de Enfermagem da Universidade de São Paulo. São Paulo, São Paulo, Brasil. http://lattes.cnpq.br/6270065902247976.
} 
Objective: to understand the perceptions of nursing professionals in relation to possible outcomes resulting from the COVID-19 pandemic for the profession. Method: qualitative study, based on Oral History, through interviews and application of a socioeconomic/professional questionnaire, conducted in the bospitalization unit of a large bealth institution, located in the city of São Paulo, capital of the state of São Paulo. Results: two relevant categories were extracted from the interviews: Belief in the strengthening of nursing in the post-pandemic and Disbelief in the improvement of nursing image in the post-pandemic. Final Considerations: professional identities are constructed through social interactions between the me (subject) and the other (social and institutional groups). This interaction is marked by conflicts that result in the reconstruction of this identity and with possible reflexes in professional practice.

Descriptors: History of Nursing. Nursing. Social Construction of Identity. Self-Identity. Identity Crisis.

Objetivo: comprender las percepciones de los profesionales de enfermería sobre los posibles resultados derivados de la pandemia de COVID-19 para la profesión. Método: estudio cualitativo, basado en la Historia Oral, a través de entrevistas y aplicación de un cuestionario socioeconómico/profesional, realizado en la unidad de hospitalización de una gran institución de salud, ubicada en la ciudad de São Paulo, capital del estado de São Paulo. Resultados: de las entrevistas se extrajeron dos categorias relevantes: Creencia en el fortalecimiento de la enfermería en el postpandemia e Incredulidad en el mejoramiento de la imagen de enfermería en el post-pandemia. Consideraciones finales: las identidades profesionales se construyen a través de interacciones sociales entre la yo (individuo) y el otro (grupos sociales e institucionales). Esta interacción está marcada por conflictos que resultan en la reconstrucción de esta identidad y con posibles reflejos en la práctica profesional.

Descriptores: Historia de la Enfermería. Enfermería. Construcción Social de la Identidad. Identidad Propia. Crisis de Identidad.

\section{Introdução}

A Organização Mundial da Saúde (OMS) declarou, em 30 de janeiro de 2020, que o surto da doença causada pelo novo coronavírus, SARS-CoV-2, constitui uma Emergência de Saúde Pública de Importância Internacional - o mais alto nível de alerta da Organização, conforme previsto no Regulamento Sanitário Internacional. Em 11 de março de 2020, a COVID-19 foi classificada pela OMS como uma pandemia e, em pouco tempo, 29 de maio de 2020, o mundo já contabilizava 5.701 .337 casos de infectados por COVID-19 e 357.688 mortes $^{(1)}$.

A gravidade da pandemia fez com que o mundo entrasse em estado de alerta, pois a doença era de rápida propagação, causando impacto em diversos setores da economia mundial. O novo coronavírus é da família de vírus que causa infecções respiratórias e provoca a doença COVID-19. Sua transmissão ocorre de pessoa para pessoa por meio de gotículas respiratórias e do contato direto ou indireto entre os indivíduos, provocando infecção pulmonar. Nos casos mais leves, pode ser comparada a um resfriado comum ${ }^{(2)}$.

É considerada a maior pandemia do século XXI. Como forma de contenção da ascensão da pandemia, foram instituídas medidas de isolamento social, principalmente do grupo de risco, que são os idosos e os indivíduos com comorbidades $^{(3)}$. A complexidade do contexto imposto pela pandemia desdobra-se em desafios aos profissionais da saúde, em especial, os profissionais da enfermagem, visto que é a categoria da área da saúde que contempla o maior quantitativo de profissionais e que permanece em tempo integral no cuidado ao paciente hospitalizado. Dessa forma, é esperado que o impacto da pandemia implique em importantes repercussões ${ }^{(4)}$.

As instituições de saúde, no contexto geral, foram as mais desafiadas diante das necessidades de diversas adaptações situacionais propostas pelos órgãos controladores, como a OMS, Organização Pan Americana da Saúde (OPAS), Agência Nacional de Vigilância Sanitária (ANVISA), órgãos municipais, estaduais e federais e órgãos de conselhos, conforme os estudos sobre a COVID-19 eram divulgados.

Em meio a esses momentos de instabilidades, mudanças, incertezas, complexidades e imprecisões, os profissionais de saúde desempenharam um importante papel na frente de combate, 
especialmente os profissionais de enfermagem, revelando sua importância nas organizações de saúde. Sua visibilidade ficou mais evidente para a população e para as mídias sociais.

Historicamente, a relação entre enfermagem e sociedade foi, e ainda é, marcada por conceitos, preconceitos e estereótipos $^{(5)}$ que forjaram, ao longo da história, várias imagens associadas à figura da enfermeira: a da "enfermeira-mãe", a da "enfermeira religiosa" e a da "enfermeira-servidora"(6). Todas elas, na visão dos autores, influenciaram, e ainda influenciam, o processo de construção identitária, bem como a compreensão de seu significado enquanto profissão da saúde composta de gente que cuida de gente.

Sem dúvida, a construção identitária de uma profissão passa pelas interações sociais entre indivíduos e pelas relações sociais estabelecidas entre estes e as instituições ${ }^{(6)}$. Nesse processo, as representações sociais adquirem significado muito importante, pois ajudam a cimentar essa identidade profissional, fortalecendo-a no imaginário coletivo.

O contexto da pandemia da COVID-19 trouxe consigo um novo olhar social para esses profissionais de enfermagem e imprimiu uma ressignificação de sua imagem profissional, haja vista as incontáveis manifestações coletivas de apoio e reconhecimento pelos esforços empreendidos no cuidado aos pacientes infectados.

Contudo, um questionamento surgiu com muita latência, suscitando a necessidade de uma investigação mais aprofundada no tocante aos processos de construção identitária pelos quais esses profissionais de enfermagem estavam passando: Como compreender os efeitos da pandemia na construção da identidade profissional desses atores sociais? Tal questionamento encontra respaldo em pesquisadores que defendem a premissa de que a identidade profissional é um processo em constante transformação, portanto, nunca acabado, é dinâmico, é baseado em múltiplas interações sociais, marcado por rupturas que promovem sua desconstrução e reconstrução em seu percurso histórico ${ }^{(5,7-10)}$.

Nesse contexto, o presente estudo teve como objetivo compreender as percepções dos profissionais de enfermagem em relação aos desfechos possíveis para a profissão decorrente da pandemia da COVID-19.

\section{Método}

Foi delineado para esta pesquisa a metodologia qualitativa, por ser a abordagem apropriada para captar as percepções dos profissionais de saúde quanto ao objeto de estudo.

O público-alvo constituiu-se de profissionais de enfermagem. O critério de inclusão baseou-se na obrigatoriedade de estarem atuando na assistência direta a pacientes acometidos pela COVID-19 em unidades de internação. Dessa forma, 30 profissionais da área de enfermagem contribuíram para este estudo, sendo 28 enfermeiros e 2 técnicos de enfermagem.

A pesquisa foi realizada na unidade de internação de uma instituição de saúde de grande porte, localizada no município de São Paulo, estado de São Paulo. Para a coleta dos dados optou-se pela entrevista gravada em áudio, individual e confidencial. A entrevista foi norteada por um questionamento central com o seguinte apontamento: "Para você, o que será da enfermagem pós-pandemia?" Também foi aplicado um instrumento com o objetivo de levantar informações sociodemográficas e profissionais sobre os participantes.

Os dados foram coletados no mês de julho de 2020. Em um primeiro momento, foi realizada a entrevista individual após a assinatura do Termo de Consentimento Livre Esclarecido (TCLE), seguida da transcrição e posterior envio aos participantes para ratificação do conteúdo das entrevistas. A segunda etapa foi o preenchimento de formulário para caracterização de dados sociodemográficos e profissionais referente aos participantes da pesquisa. $\mathrm{O}$ anonimato dos participantes foi mantido com a substituição dos nomes pela letra E de Entrevistado e de números que corresponderam à sequência das entrevistas (E1, E2, E3 ...).

A análise dos resultados foi realizada de acordo com a análise de conteúdo ${ }^{(11)}$, seguindo as etapas: pré-análise, fase de organização que 
tem por objetivo sistematizar as ideias iniciais, de modo a conduzir a um esquema preciso do desenvolvimento das operações sucessivas, num plano de análise; exploração do material, que consiste essencialmente numa operação classificatória que visa alcançar o núcleo de compreensão das entrevistas; e tratamento dos resultados obtidos e interpretados.

A pesquisa foi aprovada pelo Comitê de Ética em Pesquisa da Escola de Enfermagem da Universidade de São Paulo (CEP EE/USP), sob Parecer no 4.087.392, Certificado de Apresentação de Apreciação Ética (CAAE) 32699220.7.0000.0070, atendendo a todas as especificidades preconizadas pela Resolução no 466/2012, do Conselho Nacional de Saúde.

\section{Resultados}

Em relação ao questionário sociodemográfico e profissional, foi levantado que, em relação ao tempo de formação, 60\% dos profissionais entrevistados possuem entre 14 e 20 anos de formação, 25\% 6 a 13 anos e 15\% de 1 a 5 anos. O tempo de assistência aos pacientes diagnosticados com COVID-19 para a maioria dos entrevistados foi de cinco meses de atuação, no momento da coleta dos dados. Todos os participantes atuam somente em um emprego.

Em relação às perspectivas futuras da categoria profissional no pós-pandemia, os discursos dos entrevistados apresentaram opiniões diferentes quanto à questão levantada, sendo detectada a polarização entre duas categorias.

\section{Categoria 1 - Crença no fortalecimento da enfermagem no pós-pandemia}

As falas inseridas nesta categoria indicam o quanto os entrevistados acreditam e almejam que a enfermagem terá maior visibilidade pós-pandemia.

Eu acho que a equipe de Enfermagem vai sair muito fortalecida, muito fortalecida pelo fato do reconbecimento da população, no geral. Mas, mesmo assim, tem muita coisa a se fazer pela Enfermagem.... eu acho que ainda valorizar mais. (E10).

O que vai ser [risos]? Bom, é, eu acho assim, que em relação a enfermagem pós-pandemia vai ter oportunidades. Eu acho que vai ter oportunidades da sociedade, talvez oportunidades por parte dos nossos governantes, mas, mais ainda oportunidades pelas próprias instituições de saúde, porque elas viram todas as nossas necessidades. (E15).

Eu ainda não tenho uma resposta fixa. Mas eu achava bem no começo iria ser muito mais valorizada, porque eu achei que estava todo mundo dando valor a todos profissionais, mas achei que seria uma forma da gente ser mais valorizada. Mas acho que já não está muito ainda nesta linha de valorização. Acho que a gente conseguiu ter mais visibilidade, não como auxiliares dos médicos, como muita gente diz, acho que eles conseguiram ver um pouco a nossa atuação como enfermeiros e técnicos, a equipe de enfermagem em si, mais acho que ainda falta bastante. (E16).

Com certeza vai mudar. Mudar o modo de olhar, o cuidado com o outro, o pensar em se proteger, a proteção vai ser maior a partir de agora, já está sendo na verdade, o uso de EPIs, a gente vai fixar melhor na cabeça. Com certeza vai ser um outro olhar que a gente vai ter, com mais consciência. (E17).

Olha, eu acho que é [...] vai ser uma [...] já está sendo uma transformação, uma transformação para os profissionais, muitas pessoas estão vendo as coisas de uma forma diferente. Acho que é uma transformação. Uma visibilidade da Enfermagem para a sociedade? (E19).

Eu não quero ter um pensamento pessimista porque está sendo muito legal, a gente se sente bem em saber que a gente... somos profissionais que trazem o que... conforto para as pessoas, segurança, isso é muito bacana ter esse sentimento frente as pessoas que a gente cuida e da sociedade. Porém eu acredito que acabando a pandemia, eu acho que isso não vai se sustentar, não vai se sustentar... Acredito que vai ter uma procura grande para as pessoas procurarem a área da saúde para se profissionalizar, isso vai ter um boom mesmo, acredito nos próximos um ou dois anos, mas depois isso vai um pouco [...] ficar um pouco mais para trás porque quando você fala em doença isso traz tristeza e heroísmo ao mesmo tempo. O heroísmo está presente hoje, mas eu não sei se isso vai ficar para frente. (E20).

Acho que nós estamos vendo a vida diferente. A gente sempre se expôs a riscos, mas, diante de uma coisa tão desafiadora nos provoca questionamentos acerca do valor da vida, da nossa família, e tudo mais. (E23).

Eu acho que vai mudar bastante a enfermagem depois da pandemia. A questão hospitalar, não, mas a questão da faculdade, do ensino, essas coisas, acho que vai mudar muito. Acho que já estava tendo bastante o ensino a distância. Acho que vai aumentar muito o ensino a distância. (E24).

Então eu espero que isso aguce um pouco mais os profissionais na pesquisa. E agora sim, dentro da parte bospitalar em relação a emprego a princípio a gente ainda não viu tantas mudanças. A gente viu até contratações a mais, porém também já vi algumas demissões, então não sei, eu acho que ainda está um pouco incerto. (E25).

Bom sem dúvida vai continuar sendo um serviço essencial. Talvez eu acho que a gente tem que pensar numa forma diferente de trabalhar, uma forma diferente de captar o paciente e de cuidar também. Talvez por conta, a economia em si talvez não vá gerar tanto emprego como a gente tinha antes [...] mas eu acho que a gente vai 
ter que se reinventar em algumas coisas, nos processos de trabalbo principalmente. (E26).

Penso que existe uma grande oportunidade em a própria enfermagem se posicionar para ter a sua visibilidade de uma forma mais consolidada em ciência, na ética. Requerer mais respeito mas, se não partir da enfermagem acho difícil que esse heroísmo momentâneo, essa fama momentânea se sustente. Precisamos olhar de dentro [enfermagem] para fora [sociedade] e não o inverso. Espero que consigamos. (E29).

\section{Categoria 2-Descrença na melhora da} imagem da enfermagem no pós-pandemia

Em contrapartida com a categoria anterior, para os entrevistados incluídos na segunda categoria ficará a desejar a melhora da imagem da enfermagem mesmo pós-pandemia.

[...] eu acho que isso vai continuar igual porque boje a gente é reconbecido "nossa, o trabalho da enfermagem é muito importante". Sim, mas sempre foi muito importante. Eu acho que mais para frente essas pessoas vão esquecer novamente. Querendo ou não, a classe médica é sempre muito valorizada. Sempre foi muito valorizada. A enfermagem já atua em muitas pandemias junto com a equipe médica e tudo voltou a ser normal. (E11).

Não vai mudar nada. (E12).

Em questão de valorização, infelizmente não acredito muito por conta do governo. O governo não vê a Enfermagem diferente, por tudo que tem acontecido. Acho que até algumas famílias, as crianças que veem, vai ter aquela coisa: "ab, eu vou querer ser enfermeira", mas em relação aos profissionais de boje, acho que vai demorar um pouco ainda para serem reconbecidos, infelizmente. (E13).

Eu gostaria que ela fosse mais valorizada e autônoma em relação às instituições e também em divulgar o trabalbo dela [da enfermagem] e não ficar submissa somente a prescrições médicas e não sermos vistos apenas como beróis, apesar de na enfermagem termos heróis desde que a enfermagem existiu, no início. Mas acho que ainda falta muito, a nossa cultura ainda não está preparada e nem as nossas instituições de ensino para aceitar o que é ser enfermeiro. (E14).

De verdade, eu acho que não vai mudar muita coisa [...] Eu acho que só nesse momento as pessoas, agora, precisam de heróis, então elas "endeusaram" quem é médico e enfermeiro, mas você vê que já está diminuindo de novo e o pessoal já não está ligando muito porque, se ligasse, iam se cuidar e não está acontecendo. (E18).

Eu não tenho muitas esperanças que após a pandemia a gente vá conseguir mudar muita coisa em relação a ganbo para a Enfermagem. Eu acho que no primeiro momento as pessoas conseguiram enxergar o papel da Enfermagem, mas hoje 4 meses após a pandemia se iniciar aqui no Brasil, já se perdeu muito aquilo do começo da valorização do enfermeiro, da importância do enfermeiro na assistência à saúde. (E27).

Acho que nada vai mudar, a gente vai continuar batalhando por salários, por carga borária, da mesma forma como era antes. Como muitas coisas são muito rápidas, a gente teve um reconbecimento, um estopim, fomos chamados de heróis aí no começo, mas quando tudo isso passar, acredito que a gente vai cair novamente na trivial rotina que é a luta por salário, jornada de trabalbo e condições adequadas para trabalhar, acho que não vai mudar nada. (E30).

\section{Discussão}

Optou-se pelo método da história oral por este ser reconhecido para estabelecer relações de maior qualidade e profundidade entre o pesquisador e os participantes do estudo. Nesta pesquisa, objetivou-se revelar as narrações como ferramentas, que se configuram no tipo biográfico $^{(12)}$. Do ponto de vista teórico, a história oral é uma possibilidade de aproximação empírica com significados históricos, permitindo analisar criticamente a aplicação de teorias macrossociológicas sobre o passado ${ }^{(13)}$, de um passado não tão longínquo, mas baseada nas vivências dos sujeitos históricos no contexto do tempo presente.

Por outro lado, considerou-se que a dimensão política dos sujeitos é uma parte inseparável dos indivíduos, e apesar de prejudicada pela educação tradicional e hierarquizada, produz resistências e deflagra o jogo de poder. A essa dimensão entende-se a vida cotidiana que categoriza o indivíduo, marcando em sua própria individualidade, ligando em sua própria identidade, impondo-lhe uma lei de verdade, que devemos reconhecer e que os outros têm que reconhecer nele ${ }^{(14)}$.

Assim, a aproximação teórica entre a teoria de Claude Dubar sobre as identidades profissionais e a história oral possibilitou articular o horizonte de análise dos dados empíricos da pesquisa, ao mesmo tempo em que se valorizou a história de vida dos participantes e a construção do seu histórico-social e identitário. Desse modo, alargou-se a compreensão sobre a identidade do ser enfermeiro, no contexto de suas práticas, ancoradas no saber e no fazer cotidiano.

Os discursos dos entrevistados revelaram uma polarização entre os que acreditam numa mudança positiva para a enfermagem após o advento da pandemia de COVID-19, cuja atuação ganhou visibilidade por meio das mídias 
atingindo a sociedade em geral, e aqueles que, apesar da notória visibilidade, não acreditam que ocorrerão transformações positivas para a enfermagem no pós-pandemia.

Tal polarização se justifica pela forma como cada indivíduo percebe e interage com os grupos sociais, cujas relações são determinantes para as construções identitárias. Mesmo que essas interações ocorram entre profissionais de um mesmo grupo social, nada garante que haverá uma homogeneidade de pensamentos e percepções. A construção das identidades profissionais é um processo em constante construção, nunca acabado, permeado pelas interações sociais, uma construção forjada pela socialização ${ }^{(8)}$. A razão de se ocupar, principalmente, em compreender os processos constitutivos das identidades profissionais é porque estes defendem a tese da centralidade do trabalho na vida pessoal e do lugar eminente das identificações profissionais na vida social ${ }^{(8,16)}$.

De fato, o trabalho constitui um pilar essencial dentro do processo construtivo de uma identidade, de modo que, sua privação, seu reconhecimento ou não, o sentir-se pertencente ou não, são componentes importantes dentro do processo de construção desta identidade, pois são mediante as relações sociais estabelecidas que estes elementos ganham notoriedade e significância dentro da construção identitária. São nas interações indivíduo/instituição, indivíduo/grupos sociais e indivíduo/pacientes que essas construções se configuram, com base no modo como cada pessoa se apropria dos espaços nos quais interage e se percebe como sujeito ${ }^{(15)}$.

Dessa forma, as divergências encontradas nos discursos dos participantes deste estudo se justificam com base nessas características que a construção da identidade tem, que é ser relacional e ser marcada pela diferença. Contudo, vale esclarecer, que a diferença aqui não é sinônimo de desigualdade ou de exclusão, deve ser entendida como o elemento que favorece a identificação, que permite com que o indivíduo se localize nos grupos que compartilham as mesmas representações.

A primeira categoria identificada nos discursos de alguns dos profissionais de enfermagem diz respeito àqueles que compartilham uma percepção em comum: a de que haverá mudanças positivas na enfermagem no pós-pandemia de COVID-19. Há, nos depoimentos dos entrevistados E10, E16, E19, a evidência de um reconhecimento vinculado à imagem social da enfermagem e tudo o que ela pode vir a representar para a coletividade, demonstrando uma relação inseparável entre identidade profissional e imagem profissional. Dualidade esta, que pode ser correlacionada aos termos "Identidade para si" (como eu me enxergo dentro dos meios sociais aos quais pertenço) e "Identidade para o outro" (como o outro me vê e as representações que constrói a meu respeito e que me definem) ${ }^{(8)}$.

Essa dualidade compõe a identidade de um indivíduo e são indissociáveis, de modo que eu existo e construo minha identidade com base no olhar do outro. Entretanto, estas duas identificações - Identidade para si e Identidade para o outro - nem sempre são convergentes, isto é, minha identidade profissional e as representações que construo sobre meu ser nem sempre coincidem com a forma como o outro me vê. Esta divergência instala no indivíduo um conflito que suscita uma resolução e pode ser solucionada de duas formas: ou aceito a identificação que me é atribuída e a assimilo para minha identidade, ou recuso essa identificação e entro em um processo de negociação para modificá-la perante o outro ${ }^{(8)}$.

Claramente percebe-se no discurso dos entrevistados a preocupação com a imagem profissional construída em relação à enfermagem que, aos olhos deles, não condiz com suas identidades para si em construção. Nota-se, nesse caso, uma recusa à "identidade para o outro" e vislumbram, na pandemia, a possibilidade de reconstrução da imagem profissional da enfermagem. Para estes entrevistados, a pandemia terá como efeito positivo a melhora dessa imagem, devido à visibilidade dos esforços empenhados nas ações de cuidado aos pacientes acometidos pela Covid-19 e o reconhecimento da população em geral. Para eles, a pandemia encurtará o abismo existente entre a "identidade para si" e a "identidade para o outro".

Os excertos correspondentes aos entrevistados E15, E25 e E26, revelam outra percepção 
sobre o mesmo fenômeno. Os entrevistados apostam em mudanças positivas no âmbito das relações entre os profissionais e as instituições empregadoras. Para eles, as instituições devem valorizar mais os seus profissionais, oferecendo suporte para melhor exercício da profissão.

A luta pelo reconhecimento da importância da enfermagem para o cuidado em saúde já é um movimento de longa data. É uma luta travada entre a "identidade para si", que representa a identidade profissional em construção dos profissionais que atuam na instituição, e a "identidade para o outro", correspondente à imagem social que a instituição constrói por meio de representações do que é ser enfermeiro. Essa relação de trabalho é fonte constante de conflitos e lutas. Na fala desses entrevistados nota-se que está instalada uma crise nessa relação.

Posto que, na construção das identidades profissionais o trabalho desempenha um papel extremamente importante, a instituição empregadora tem um papel igualmente importante na construção dessas identidades, uma vez que, o indivíduo, imerso nesse contexto de trabalho, passa a ter maiores interações sociais e estas terão forte influência na construção da "identidade para si”, ${ }^{(8)}$. O conflito entre esses dois polos - profissionais e instituições - relaciona-se a sistemas de representação com estreita ligação com as relações de poder ${ }^{(16)}$, e é apenas no exercício da profissão que ela se consolida, pois os resultados decorrentes dessas interações impactam diretamente na construção da identidade profissional do grupo atuante naquela instituição $^{(8)}$. Assim, o apontamento dos entrevistados adquire relevância, pois, uma profissão é construída sobre e mediante uma prática ${ }^{(16)}$, que carece de reconhecimento. Desse modo, é pertinente afirmar que a construção da identidade profissional depende do retorno de informações vinda dos outros ${ }^{(14)}$.

Nota-se, aqui, a mesma tendência do grupo analisado anteriormente, isto é, a recusa a uma identidade atribuída pelo outro, divergente da identidade atribuída para si, e a busca por reconhecimento por parte da instituição. Enxergam, na pandemia, a possibilidade de alinhamento dessas identificações.

Nos excertos seguintes, referentes aos discursos dos entrevistados E17, E23 e E29, observa-se uma reflexão sobre as próprias práticas profissionais proporcionadas pela não aceitação das identificações atribuídas pelo outro. O olhar externo faz eu me enxergar e refletir sobre quem sou e como me vejo nesse processo construtivo de minha identidade profissional, e minhas representações de mim mesmo são postas em cheque, suscitando em mim uma necessidade de revisá-las e, possivelmente, reconstruí-las baseada nesses olhares externos.

O "eu" dentro do processo de construção da identidade profissional tende à estabilização e fixação, contudo, o "outro" tende a desestabilizar e subverter esse processo ${ }^{(8)}$. Dessa forma, a fixação é uma tendência e, ao mesmo tempo, uma impossibilidade, pois agentes externos estão sempre produzindo momentos de crises, que encontram no espaço institucional do trabalho um campo fecundo para sua instalação.

Para estes entrevistados, o advento da pandemia trouxe consigo a necessidade urgente de reflexão sobre suas próprias práticas de cuidado. Isso deve-se ao fato do vírus que provoca a doença COVID-19 ser um agente infeccioso desconhecido, pois não havia na literatura um protocolo de manejo para lidar com o vírus, tampouco com os pacientes infectados. O conhecimento foi construído conforme o vírus era estudado. As incertezas geradas pela falta de conhecimento atingiram todos que atuavam no cuidado aos pacientes com COVID-19, e principalmente aqueles que estão na linha de frente.

Essa situação vivenciada por este grupo de entrevistados encontra amparo em estudo que afirma que o indivíduo, anteriormente tido como possuidor de uma identidade profissional unificada e estável, está se tornando um indivíduo fragmentado ${ }^{(18)}$. Esta fragmentação, no que concerne à construção das identidades profissionais, é notória neste grupo. Os saberes, tidos como sólidos e estáveis, desestabilizam essas identidades frente à nova situação de pandemia e lhes imprime a necessidade do resgate de algum setor 
dessa identidade em construção, até então estável, e reconstruí-la. Afinal, a construção identitária é um processo vivo e pulsante que não permite sua estabilização permanente.

Os excertos referentes aos depoimentos dos entrevistados E20 e E24 corroboram a perspectiva positiva dos demais entrevistados discutidos anteriormente, quando vislumbram um futuro para a enfermagem no pós-pandemia, no qual outros indivíduos irão se interessar pela formação profissional de enfermagem graças à visibilidade positiva que esta vem obtendo na atuação de enfrentamento da pandemia de COVID-19. Estes entrevistados acreditam que a imagem profissional da enfermagem reconstruída pela sociedade contribuirá para que outros atores sociais se interessem pela área. Afinal, assim como a identidade profissional é construída mediante a interação entre o eu e a sociedade ${ }^{(8,15-17,19)}$, a construção da imagem profissional segue esta mesma lógica.

As identificações com os grupos de referências (aqueles grupos sociais que não fazem parte do grupo de pertencimento do indivíduo) são determinantes para que os indivíduos se articulem para fazer parte desses grupos, objeto de desejo ${ }^{(8)}$. Essa ruptura do indivíduo com os modelos e padrões estabelecidos pelos grupos de pertencimento e que garantem a continuidade da profissão por gerações numa família é um movimento importante dentro dos processos constitutivos das identidades profissionais. Nisso, apostam os entrevistados E20 e E24, quando afirmam que haverá maior procura pela profissionalização da área da enfermagem e, graças a essas interações sociais, as identidades são (re) construídas de forma heterogênea e de acordo com as diversas apropriações das experiências vividas pelo sujeito ao longo de sua jornada ${ }^{(15)}$.

No outro extremo dessa polarização, na segunda categoria encontrada nos discursos de alguns entrevistados, "descrença na melhora da imagem da enfermagem no pós-pandemia", localizam-se aqueles indivíduos que não acreditam numa mudança positiva para a enfermagem.

Os entrevistados que, em seus discursos, apresentaram descrença quanto ao futuro da enfermagem também vivenciam um processo de crise, caracterizada pela existência de um conflito instalado entre a "identidade para si" e a "identidade para o outro", no qual as representações sociais que definem a "identidade para si" não coincidem com as representações que a "identidade para o outro" constrói sobre mim ${ }^{(8)}$.

Sendo a identidade profissional uma construção que compreende a capacidade do indivíduo se reconhecer e a possibilidade de ser reconhecido pelo outro ${ }^{(17)}$, este conflito marca de forma clara uma polarização entre o modo como a pessoa se vê e o modo como os outros a veem. Sobre isto, um estudo cita:

\begin{abstract}
As situações críticas são, por excelência, o momento em que nossa identidade e suas fragilidades são reveladas: quando somos submetidos a expectativas contraditórias, quando perdemos nossas identificações tradicionais, quando entramos em um novo sistema de normas. Estes conflitos são provas difíceis para nossa identidade e podem comprometê-la ${ }^{(14: 46)}$.
\end{abstract}

Os conflitos, uma vez instalados, suscitam uma solução, pois não podem perdurar permanentemente. Tais processos identificatórios não coincidentes, descritos como identidades em desacordo, requerem do indivíduo estratégias identitárias que visam diminuir o abismo entre as duas identidades contrastantes e podem assumir duas formas: a de transações externas (ou objetivas) ou a de transações internas ao indivíduo. A estratégia das transações externas, entre o indivíduo e os outros agentes sociais, visa acomodar a "identidade para si" à "identidade para o outro". A de transações internas ao indivíduo, busca salvaguardar um pouco da identidade construída e o desejo de construir para si novas identidades; esse processo visa assimilar a "identidade para o outro" à "identidade para si". Portanto, inverso ao primeiro processo ${ }^{(8)}$. A descrença relatada pelos entrevistados reflete claramente os ajustes feitos em suas identidades profissionais diante do conflito instalado e evidenciam sua opção pela transação externa, visando diminuir a distância entre as identificações e aceitando a identificação feita pelo outro:

Não vai mudar nada. (E12).

Em questão de valorização, infelizmente não acredito muito por conta do governo [...]. (E13). 
A prevalência do olhar do "outro" sobre a identidade para mim imprimiu nos entrevistados o ajuste de suas identidades ao olhar externo. Tal fato reforça, claramente, que é impossível separar os aspectos individuais dos aspectos relacionais e sociais da identidade e que nossa identidade profissional é construída e reconstruída, de uma forma ou de outra, pela negação ou pela aceitação, com base no olhar do outro. Essas interações sociais entre o eu e o outro constituem-se elemento imprescindível para a construção das identidades profissionais.

Dessa forma, os reflexos oriundos dos conflitos entre o "eu" e "o outro" perante estes grupos de entrevistados e os ajustes feitos por eles têm um grande potencial para determinar suas práticas profissionais no cuidado ao paciente, na medida em que suas identidades profissionais são desconstruídas e reconstruídas mediante essas interações sociais. Assim, toda vez que, em momentos de conflitos, o indivíduo encontra a solidariedade de outros e se identifica como parte de um grupo, sua identidade é reforçada e garantida ${ }^{(17)}$, bem como uma situação contrária pode configurar em perda da identidade para si.

A limitação deste estudo está em não constituir um instrumento que possa mensurar (considerando esta possibilidade) o quanto essas interações, apresentando convergências ou divergências entre a "identidade para si" e a "identidade para o outro", refletem na prática profissional destes indivíduos. Contudo, é pertinente inferir que, ocorrendo um alinhamento entre a identidade profissional para mim e a identidade profissional para os outros, há a possibilidade de refletir em boas práticas profissionais.

\section{Considerações Finais}

A identidade profissional caracteriza-se como construção contínua, inacabada e não linear, envolvendo a relação do indivíduo e os grupos sociais com os quais interage. Os achados deste estudo comprovam que esse processo relacional é inseparável e permeado por momentos de conflitos nos quais esta identidade é posta à prova, é questionada, fazendo com que o "eu" entre em um processo de reconstrução identitária.
Há uma polarização instalada entre os entrevistados, mesmo que pertencentes à mesma instituição, e isso reflete claramente as interações relacionais estabelecidas entre cada indivíduo ou grupos de indivíduos e a instituição, isto é, entre o "eu" e os "outros", sendo este último capaz de influenciar as identidades em construção. Isso evidencia que cada indivíduo percebe o olhar do outro, a instituição, de forma diferente.

Da mesma forma ocorre quando se refere à interação entre os entrevistados e os grupos sociais, pois é mediante essa relação social estabelecida que as identidades profissionais são reconstruídas num movimento para tentar aproximar as fronteiras entre a identidade para mim e a identidade para os outros. Ocorrendo a aproximação entre essas identidades conflitantes, torna-se possível pensar em identificação e pertencimento aos grupos sociais e, também, numa possibilidade de reforço dessa identidade.

\section{Colaborações:}

1 - concepção, projeto, análise e interpretação dos dados: Ellen Maria Hagopian, Fábio Soares Melo, Genival Fernandes de Freitas, Viviane Barrére Martin Taffner, Margarete Maria Rodrigues e Marcus Vinícius de Lima Oliveira;

2 - redação do artigo e revisão crítica relevante do conteúdo intelectual: Ellen Maria Hagopian, Fábio Soares de Melo e Genival Fernandes de Freitas;

3 - aprovação final da versão a ser publicada: Ellen Maria Hagopian, Fábio Soares de Melo e Genival Fernandes de Freitas.

\section{Referências}

1. Organização Pan-Americana de Saúde. Folha Informativa sobre COVID-19 [Internet]. Brasília: OPAS/OMS; 2020 [cited 2020 Dec 20]. Available from: https://www.paho.org/bra/index. php?option $=$ com_content\&view $=$ article $\&$ id $=6101$ : covid19\&Itemid $=875$

2. Santos C. A Construção Social do Conceito de Identidade Profissional. Interacções [Internet]. 2005 Apr [cited 2020 Aug 10];8:123-44. Available from: https://www.interacoes-ismt.com/index. $\mathrm{php} /$ revista/article/view/145/149 
3. Zhou F, Yu T, Du R, Fan G, Liu Y, Liu Z, et al. Clinical course and risk factors for mortality of adult inpatients with COVID-19 in Wuhan, China: a retrospective cohort study. Lancet. 2020;395(10229):1054-62. DOI:10.1016/501406736(20)30566-3

4. Rafael RMR, Mercedes Neto, Carvalho MMB, David HMSL, Acioli S, Faria MGA. Epidemiologia, políticas públicas e pandemia de Covid-19: o que esperar no Brasil? Rev Enferm UERJ. 2020;28:e49570. DOI: $10.12957 /$ reuerj. 2020.49570

5. Padilha MICS. A Enfermagem em foco: perspectivas no ensinar e aprender a história da profissão. In: Congresso Brasileiro de Enfermagem, 56, 2004, Gramado, Rio Grande do Sul. Anais Gramado: Associação Brasileira de Enfermagem; 2004. p. 24-9.

6. Campos PFS, Oguisso T. La Identidade e exercício profissional. In: Oguisso T, Schmidt MJ, organizadoras. O exercício da enfermagem: uma abordagem ético-legal. Rio de Janeiro: Guanabara Koogan; 2010. p. 301-11.

7. Barreira IA, Baptista SS. The movement for reassessing education and research in nursing history. Rev Bras Enferm. 2003;56(6):702-6. DOI: 10.1590/S0034-71672003000600024

8. Dubar C. A Socialização: construção das identidades sociais e profissionais. São Paulo: Martins Fontes; 2005.

9. Nascimento MAV. Dimensões da identidade profissional docente na formação inicial. Rev Port Pedag. 2007;(41-42):207-18. DOI: 10.14195/1647-8614_41-2_9

10. Sánchez AC, Díaz DPG, Gómez STG, Vargas RAV. Nursing: Symbols, Stereotypes and Social Image, "A Transgenerational Vision" of Nurses and Physicians at the Fundación Santa Fe de Bogotá, a Tribute to Four Decades of Service. Actual Enferm [Internet]. 2012 [cited 2020 Aug 10];15(4):9-19. Available from: https://repository.
udca.edu.co/bitstream/11158/3595/1/ART.\%2090. pdf

11. Bardin L. Análise de conteúdo. Lisboa: Edições 70; 2016.

12. Meihy JC, Holanda F. História Oral: como fazer, como pensar. São Paulo: Contexto; 2019.

13. Pinsky CB, organizadora. Fontes Históricas. São Paulo: Contexto; 2014.

14. Almeida DB, Silva GTR, Freitas GF, Ramos FRS, Albuquerque GL, Almeida IFB, et al. Recursos de disciplinarização na enfermagem: um estudo histórico e foucaultiano. Acta Paul Enferm. 2017;30(6):598-606. DOI: https:// doi.org/10.1590/1982-0194201700084

15. Silva MLR, Silva Junior JA. A formação das identidades docentes entre estudantes do curso de pedagogia. Int Stud Law Educ [Internet]. 2019 [cited 2020 Aug 10];(31-32):123-32. Available from: http://www.hottopos.com/isle31_32/123132MaluJ.pdf

16. Silva MRL. Aspectos sócio-afetivos que interferem na construção da identidade do professor. In: Silva ER, Uyeno EY, Abud MJ, organizadoras. Cognição, Afetividade e Linguagem. Taubaté: Cabral; 2007. p. 235-60.

17. Melucci A. O jogo do eu: a mudança de si em uma sociedade global. São Leopoldo: Unisinos; 2004.

18. Silva TT, Hall S, Woodward K. Identidade e diferença: a perspectiva dos estudos culturais. 15a ed. Petrópolis: Vozes; 2014.

19. Hall S. A identidade cultural na pós-modernidade. 12a ed. Rio de Janeiro: Lamparina; 2019.

Recebido: 26 de dezembro de 2020 Aprovado: 25 de maio de 2021 Publicado: 15 de julho de 2021

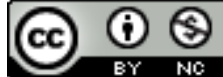

A Revista Baiana de Enfermagem utiliza a Licença Creative Commons - Atribuição-NãoComercial 4.0 Internacional. https://creativecommons.org/licenses/by-nc/4.0/ Este artigo é de acesso aberto distribuído sob os termos da Licença Creative Commons (CC BY-NC). Esta licença permite que outros remixem, adaptem e criem a partir do seu trabalho para fins não comerciais. Embora os novos trabalhos tenham de lhe atribuir o devido crédito e não possam ser usados para fins comerciais, os usuários não têm de licenciar esses trabalhos derivados sob os mesmos termos. 